\title{
Internet Addiction of Adolescent and Treatment: Mini Review
}

\section{Priyono D*, Putri TH and Fradianto I}

Department Community and Mental Health Nursing, Tanjungpura University, Indonesia

*Corresponding author: Djoko Priyono, Department Community and Mental Health Nursing, Tanjungpura University, Jl. Prof. DR. H. Nawawi, Pontianak, West Kalimantan, Indonesia, Tel : +628121550207; Email: djoko.priyono@ners.untan.ac.id

\section{Mini Review \\ Volume 5 Issue 1}

Received Date: April 17, 2021

Published Date: April 28, 2021

DOI: $10.23880 / \mathrm{mhrij}-16000143$

\section{Abstract}

Internet Addiction is a new addiction and it is a mental health problem current issue that could be recommended into DSM-V. There are some dimensions of physical, psychological, and emotional disturbances that arise due to internet addiction. Excessive use, withdrawal effect, tolerance, negative repercussions. Based on literature research, internet addiction on adolescents has become the main research topic in various countries. There are several more approaches that could be applied Non-psychological, Psychological Approaches: Motivational Interviewing (MI) Reality Therapy, Community Reinforcement and Family Training, Acceptance and Commitment Therapy (ACT).

Keywords: Internet Addiction, Adolescent; Treatment

Abbreviations: MI: Motivational Interviewing; ACT: Acceptance and Commitment Therapy; ASAM: American Society of Addiction Medicine; SSRI: Selective Serotonin Reuptake-Inhibitor; ADHD: Attention-Deficit Hyperactivity Disorder; YIAS: Young Internet Addiction Scale.

\section{Internet Addiction}

Internet Addiction is a new addiction and it is a mental health problem that involves the same signs and symptoms as other addiction [1]. For that reason, internet addiction is supported to be listed into DSM-V [2]. Some reviews also state that internet addiction is a current issue that could be recommended into DSM-V [3].

The American Society of Addiction Medicine (ASAM) [4] published a latest definition of addiction as a chronic brain disorder and officially proposed that addiction was not limited to substance use [5] Conceptually, Internet Addiction is counted as compulsive-impulsive spectrum disorder category that involves online and offline computer use. Another opinion states that the most common definition of internet addiction is a technology addiction defined as a nonchemical addiction or a behavior that involves interaction between human and machine [6].

A person who is addicted to the internetmustmeetseveral criteria, which are, playing game excessively, becoming a part of a chat room for porn, and actively accessing email/ text messaging [3]. The other opinion agrees to the idea that activities considered as internet addiction are online game, social media, online gambling, online shopping, and virtual sex [7]. Besides, other diagnostic criteria needed to claim that someone is addicted to the internet are busy with internet activities, the increase of time spent to access internet, fail to control internet use, and feel anxious, gloomy, depress, and irritable when trying to reduce or stop internet usage [8].

There are four dimensions of physical, psychological, and emotional disturbances that arise due to internet addiction. First, Excessive use, the loss of individual time control and ignorance against the basic motivations such as eating, personal hygiene, romantic relationship, etc. Second, withdrawal effect, the emotional and psychological effects 


\section{Mental Health \& Human Resilience International Journal}

when an individual could not access the internet. Third, tolerance, the increase on internet usage to meet individual satisfaction. Fourth, negative repercussions, the negative effects on oneself, such as stating argument and lies to cover the internet usage duration, individual social isolation as the consequences of internet usage and physical fatigue due to the ling duration of internet usage [9]. In addition to the mentioned criteria, another belief states that someone is considered addicted to the internet if he spend six hours or more per day on the internet and has last for at least three months; the average of the internet usage is 38 hours or more per week $[9,10]$.

\section{Internet Addiction of Adolescents}

Based on literature research, internet addiction on adolescents has become the main research topic in various countries. Because adolescents of high school level lack adequate control of themselves, the poor self-regulation, and low cognition compared to young adults in colleges [11]. Besides, adolescents at the High School level have the equal desire to be as free as adults, are under the process of psychological maturation, and the effortlessness in accessing the internet has also become the supporting factor of adolescents getting addicted to the internet [12]. Qualitative research conducted on ten adolescents in Taiwan found that most teenagers agree that the internet is the primary source of knowledge and an object to release stress [13].

For teenagers who are addicted to the internet tend to be poor in self-control, it would be hard for them to stop using the internet because it is comfortable and could help them run away from problems [13]. This thing leads to education problems at school, problems at home, work, health, and interpersonal relationship. Besides, they would withdraw themselves away from surrounding environment, problems related to school, health, family, and would have time management ability downgrade $[13,14]$. Other issues occurring due to internet addiction are the downgrade of academic achievements, emotional and psychiatric problems such as ADHD, depression, anxiety, obsessive-compulsive symptoms, and suicidal [5].

\section{Treatment for Internet Addiction}

It is written in the book "Internet Addiction: Symptoms, Evaluation, and Treatment", that the applicable strategy is intervention through cognitive-behavior approach, determining internet usage pattern and changing it to a new schedule, performing other activities that encourage patients to not access the internet, staying away from certain applications, using reminder cards to remind the patients about the dangers of internet addiction, involving supporting group to compensate the lack of social support including into family therapy. However, the clinical evidence of the benefits of each strategy is not stated clearly [15]. There are several more approaches that could be applied.

\section{Non-Psychological}

Specifically, Selective Serotonin Reuptake-Inhibitor (SSRI) has been applied to solve psychiatric problem as the consequences of internet addiction, such as depression and anxiety [16]. This statement is supported by the research results on 14 respondents that use Escitalopram (from SSRI) for treatment of impulsive-compulsive internet usage disorder. There is a significant decrease in the results of the treatment. The average internet usage of 36.8 hours/week decreases to 16.5 hours/week [5]. Other research uses bupropion (a non-tricyclic antidepressant), which resulted in the desire to decrease internet gaming after six weeks. Another study utilizes a psycho stimulant drug on 62 kids in Korea who suffer from online game addiction and diagnosed with attention-deficit hyperactivity disorder (ADHD). The results show that the eight weeks treatment resulted in the decrease of Young Internet Addiction Scale (YIAS-K) and internet usage. The results of this study also suggest the use of psycho stimulant drug to treat internet addiction [17]. Several kinds of literature related to the pharmacology approach above have not found standard pharmacology therapy in internet addiction treatment. Other researches state that pharmacology therapy could be replaced with physical exercise. This physical exercise could reduce the dopamine level that at the same time could decrease the desire to use internet [18].

\section{Psychological Approaches}

Based on literature research, there are several therapies to treat internet addiction. Motivational Interviewing (MI) is a client-centered method that could increase selfmotivation in order to improve and explore the skills of the clients in solving problems [19]. This technique is developed to help individual reduce addictive behavior and explore new skills. The applicable methods are by applying openended questions, active listening, giving affirmations, and concluding individual skills to have improvement [20]. Other research results suggest the Reality Therapy as the therapy for internet addiction [21]. This therapy encourages an individual to choose their life by committing to change their behavior. The study results show that Reality Therapy is effective to decrease internet addiction level and increase the self-esteem of 25 Korean students who suffer from internet addiction [21]. A study also suggests that an intervention that involves family member or peers, such as Community Reinforcement and Family Training could improve the motivation of an internet addiction patient in reducing internet usage [22]. 


\section{Mental Health \& Human Resilience International Journal}

Besides, other therapy such as Acceptance and Commitment Therapy (ACT) combined with several physical activities could be an intervention for adolescents with internet pornography addiction. The research results show $85 \%$ of addiction reduce and these results last up to 3 months after follow up [23]. Most addiction interventions are conducted through cognitive-behavioral approach. Internet addiction is suggested to be treated with CBT because it shows good results in decreasing addiction on gambling, compulsive shopping, and bulimia nervosa [24]. This thing agrees to the results of a research conducted on 29 High School students who apply CBT to solve internet addiction. The results show that the internet addiction score on the experiment group is lower compared to the control group after the CBT intervention [25].

\section{Conclusion}

In addition to the approaches above, adolescents who suffer from internet addiction must be given promotive and preventive actions through knowledge and factual information provisions regarding the consequences of excessive internet usage. Adolescents are more attentive and responsive if new information is delivered through audiovisual media. The effort in taking care of adolescents who suffer from internet addiction could be in the form of providing family therapy.

\section{References}

1. Lim JA, Gwak AR, Park SM, Kwon JG, Lee JY, et al. (2015) Are Adolescents with Internet Addiction Prone to Aggressive Behavior? The Mediating Effect of Clinical Comorbidities on the Predictability of Aggression in Adolescents with Internet Addiction. Cyberpsychol Behav Soc Netw 18(5): 260-267.

2. Kuss DJ, Van Rooij AJ, Shorter GW, Griffiths MD, Van de Mheen D (2013) Internet addiction in adolescents: Prevalence and risk factors. Computers in Human Behavior 29(5): 1987-1996.

3. Block JJ (2008) Issues for DSM-V: Internet addiction. American Journal of Psychiatry 165(3): 306-307.

4. (2017) American Society of Addiction Medicine. Public Policy Statement: Definition of Addiction.

5. Dell Osso B, Hadley S, Allen A, Baker B, Chaplin WF, et al. (2008) Escitalopram in the treatment of impulsivecompulsive Internet usage disorder: an open-label trial followed by a double-blind discontinuation phase. J Clin Psychiatry 69(3): 452-456.

6. Widyanto L, Griffiths MD (2006) Internet addiction: a critical review. International Journal of Mental Health and Addiction 4(1): 31-51.

7. Wu CY, Lee MB, Liao SC, Chang LR (2015) Risk Factors of Internet Addiction among Internet Users: An Online Questionnaire Survey. PloS One 10(10): 0137506.

8. Beard KW (2005) Internet addiction: a review of current assessment techniques and potential assessment questions. Cyberpsychol Behavior 8(1): 7-14.

9. Young KK (2009) Internet Addiction: A New Clinical Phenomenon and its Consequences. American Behavior Scientist 48(4): 402-415.

10. Tao R, Huang X, Wang J, Zhang H, Zhang Y, et al. (2010) Proposed diagnostic criteria for internet addiction. Addiction 105(3): 556-564.

11. Xu J, Shen L, Yan C, Hu H, Yang F, et al. (2012) Personal characteristics related to the risk of adolescent internet addiction: a survey in Shanghai, China. BMC Public Health 12(1): 1106.

12. Kim K (2013) Association between Internet overuse and aggression in Korean adolescents. Pediatr Int 55(6): 703-709.

13. Tsai CC, Lin SS (2004) Internet Addiction of Adolescents in Taiwan: An Interview Study. Cyber Psychology \& Behavior 6(6): 649-652.

14. Tsai HF, Cheng SH, Yeh TL, Shih CC, Chen KC, et al. (2009) The risk factors of Internet addiction-A survey of university freshmen. Psychiatry Res 167(3): 294-299.

15. Cash H, Rae CD, Steel AH, Winkler A (2012) Internet Addiction: A Brief Summary of Research and Practice. Curr Psychiatry Rev 8(4): 292-298.

16. Arisoy $O$ (2009) Internet addiction and its treatment. Current Approaches in Psychiatry. 1(1): 55-67.

17. Han DH, Hwang JW, Renshaw PF (2010) Bupropion sustained release treatment decreases craving for video games and cue-induced brain activity in patients with Internetvideo game addiction. Exp Clin Psychopharmacol 18(4): 297-304.

18. Lanjun Z (2009) The applications of group mental therapy and sports exercise prescriptions in the intervention of Internet addiction disorder. Psychological Science 32(3): 738-741.

19. Miller WR, Rollnick S (2002) Motivational interviewing: preparing people for change. $2^{\text {nd }}$ (Edn.), New York: Guilford Press. 


\section{Mental Health \& Human Resilience International Journal}

20. Miller NH (2010) Motivational interviewing as a prelude to coaching in healthcare settings. J Cardiovasc Nurs 25(3): 247-251.

21. Kim JU (2007) A reality therapy group counseling program as an Internet addiction recovery method for college students in Korea. International Journal of Reality Therapy 26(2): 3-9.

22. Peukert P, SieslackS, Barth G, Batra A (2010) Internet-and computer game addiction: Phenomenology, comorbidity, etiology, diagnostics and therapeutic implications for the addictives and their relatives. Psychiatr Prax 37(5): 219-
224.

23. Wieland DM (2005) Computer Addiction: Implications for Nursing Psychotherapy Practice. Perspect Psychiatr Care 41(4): 153-161.

24. Abreu CN, Goes DS (2011) Psychotherapy for Internet addiction. In: Young KS \& de Abreu CN (Eds.), Internet addiction: A handbook and guide to evaluation and treatment. US: John Wiley \& Sons Inc.

25. Cao FL, Su LY, Gao XP (2007) Control study of group psychotherapy on middle school students with Internet overuse. Chinese Mental Health Journal 21(5): 346-349. 